\title{
Morphologic Subtyping of Papillary Renal Cell Carcinoma: Correlation with Prognosis and Differential Expression of MUC1 between the Two Subtypes
}

Xavier Leroy, M.D., Laurent Zini, M.D., Emmanuelle Leteurtre, M.D., Farid Zerimech, M.D., Nicole Porchet, Ph.D., Jean-Pierre Aubert, Ph.D., Bernard Gosselin M.D., Marie-Christine Copin, M.D., Ph.D

Departments of Pathology (XL, EL, MCC, BG), Urology (LZ), Molecular Biology (FZ, NP, JPA), Lille University Hospitals and the Unity INSERM U560 (XL, EL, MCC, NP, JPA), CHR-U, Lille, France

Papillary renal cell carcinoma is now a wellestablished entity with distinct histological and cytogenetic features. A subdivision has been proposed in correlation with prognosis. Type 1 is the most frequent subtype and appears to have a better prognosis than Type 2 . The subdivision is based on microscopic criteria. To investigate these 2 types of papillary renal cell carcinoma, we have compared the clinical features, ancillary factors (TNM stage, Fuhrman grade), survival and MUC1 expression in 25 Type 1 and 12 Type 2 papillary renal cell carcinomas. Type 2 tumors were significantly associated with a higher Fuhrman grade (Grade III frequent; $P<.001)$. Type 2 tumors were also associated with a poorer prognosis than Type 1 $(P<.005)$. Fuhrman grade was significantly associated with prognosis $(P<.005)$. The type and the prognosis were not correlated with the TNM stage. We have shown a differential expression of MUC1 between Type 1 and Type 2 with a polarized expression in Type 1 and a rare expression in Type 2 . In conclusion we confirm that the morphologic sub-typing and Fuhrman grade are valuable factors of outcome of papillary renal cell carcinomas and that MUC1 immunostaining is useful in differentiating Type 1 and Type 2 tumors.

Copyright () 2002 by The United States and Canadian Academy of Pathology, Inc.

VOL. 15, NO. 11, P. 1126, 2002 Printed in the U.S.A.

Date of acceptance: August 7, 2002.

Address reprint requests to: Xavier Leroy, M.D., Service d'Anatomie Pathologique, Faculté de médecine, pôle recherche, Rue Polonovski, CHR-U, 59045 Lille, France; e-mail: x-leroy@chru-lille.fr; fax: 33-3-2062-6947.

DOI: $10.1097 / 01 . M P .0000036346 .88874 .25$
KEY WORDS: MUC1, Nuclear grade, Papillary renal cell carcinoma, Prognosis.

Mod Pathol 2002;15(11):1126-1130

Papillary renal cell carcinoma is the second most frequent malignant neoplasm of the adult kidney. It accounts for $10-15 \%$ of all renal carcinomas (1). Papillary renal cell carcinoma is now a wellestablished entity with specific morphological, immunohistochemical, and cytogenetic features. Classical prognostic factors used for renal carcinomas are the TNM stage and the Fuhrman grade. Usually, papillary renal cell carcinoma has been considered to have a better prognosis than clear renal cell carcinoma (1-2). Delahunt and Eble (3) have proposed to divide papillary renal cell carcinomas in two morphological types. Type 1 tumor is characterized by small cuboidal cells covering thin papillae with a single line of uniform nuclei and small nucleoli. In Type 2 tumors, the papillae are covered by large eosinophilic cells with pleomorphic nuclei, prominent nucleoli, and nuclear pseudostratification (3). Recently studying a series of 66 cases, Delahunt et al. (4) showed that this morphologic subtyping is an independent predictive factor of outcome. Indeed, Type 2 was associated with a significantly higher Fuhrman grade and a poorer prognosis (4).

MUC1 is a large transmembrane glycoprotein expressed in many normal and tumor epithelial cells. MUC1 is frequently overexpressed in carcinoma and is associated with tumor progression and poorer prognosis (5-6). In clear renal cell carcinoma, MUC1 is overexpressed, and the level of expression is associated with the Fuhrman grade and with the tumor progression (7-9).

The current study was performed to investigate the prognostic value of histologic typing in papillary renal cell carcinoma and to evaluate the expression of MUC1 in the two types. 


\section{MATERIALS AND METHODS}

\section{Case Selection}

All of the cases of papillary renal cell carcinoma (37 cases) in the archives of the Department of Pathology, Lille University hospital, France, from January 1992 to December 2000 were investigated. All histological slides were reviewed (XL). Cytologic nuclear grading was applied as described by Fuhrman et al. (10). The subtype was determined using the criteria proposed by Delahunt and Eble (3-4). All tumor stages were defined using the TNM classification (UICC, 1997). All of the patients were treated by radical nephrectomy, and all patients' histories and follow-up were recorded.

\section{Immunohistochemistry}

Immunohistochemistry (IHC) was performed on formalin-fixed, paraffin-embedded tissue sections of $4-\mu \mathrm{m}$ thickness using an automated immunostainer (ES, Ventana medical systems, Strasbourg, France). After deparaffinization, IHC was performed using a three-step indirect process based on streptavidin-biotin complex. The primary antibody used is directed against MUC1. Antibody to MUC1 recognizes the tandem repeat sequences (monoclonal $L I C R-L O N-M 8$, pretreatment by microwave 20 min, dilution 1/50). This antibody was a gift from the Ludwig Institute for Cancer Research (Dr. D. Swallow, London, UK). The sections were incubated for 32 minutes with goat serum to block the nonspecific antibody-binding sites. Endogenous biotin was blocked by adding an excess amount of avidin, followed by washing and addition of free biotin. Slides were counterstained with hematoxylin. Positive and negative controls were used. Negative controls consisted of (1) slides run without the primary antibody and (2) negative normal renal structures (glomeruli, proximal convoluted tubules). Normal bronchus was used as external positive control, and distal convoluted tubules, as internal positive control.

A tumor was judged positive if $>5 \%$ of tumor cells were stained.

\section{Statistical Analysis}

Results are presented as mean and range. The associations of age and tumor size with other clinical variables were tested with the nonparametric Kruskall-Wallis test or Mann-Whitney test. A $\chi^{2}$ test or Fisher's exact correction, as appropriate, was used to analyze the associations between sex, Fuhrman grade, pT category, and MUC1 expression. Survival curves were constructed according the method of Kaplan-Meier. Differences between the curves were assessed using the log rank test. A $P$ of $<.05$ was considered statistically significant. Statistical analyses were performed using SPSS software, version 9.0 (SPSS, Chicago, IL).

\section{RESULTS}

\section{Patients and Tumor Classification}

Patients were 29 men and 8 women with a mean age of 60 years (range, 27 to $81 \mathrm{y}$ ) at time of diagnosis. The mean size of tumors was $5.2 \mathrm{~cm}$ (range, 2 to $11 \mathrm{~cm}$ ). Twenty-five tumors were Type 1 (Fig. 1), and 12 tumors were Type 2 (Fig. 2). There were 19 men and 6 women with Type 1 tumors and 10 men and 2 women with Type 2 tumors.

Pathological details are summarized in Table 1.

The mean follow-up period was 35.6 months (range, 6 to $86 \mathrm{mo}$ ). During the follow-up, six patients (16.2\%) developed metastases. Five of these patients died of the disease, one was alive with metastasis. Four patients died of unrelated cause. Five of 6 patients with metastases had a Type 2

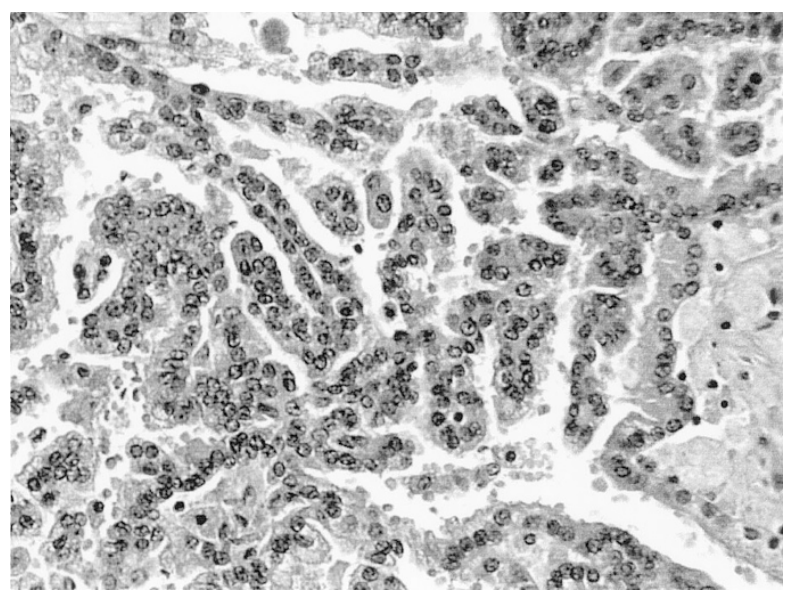

FIGURE 1. Type 1 papillary renal cell carcinoma: thin papillae covered by small basophilic cells with round nuclei.

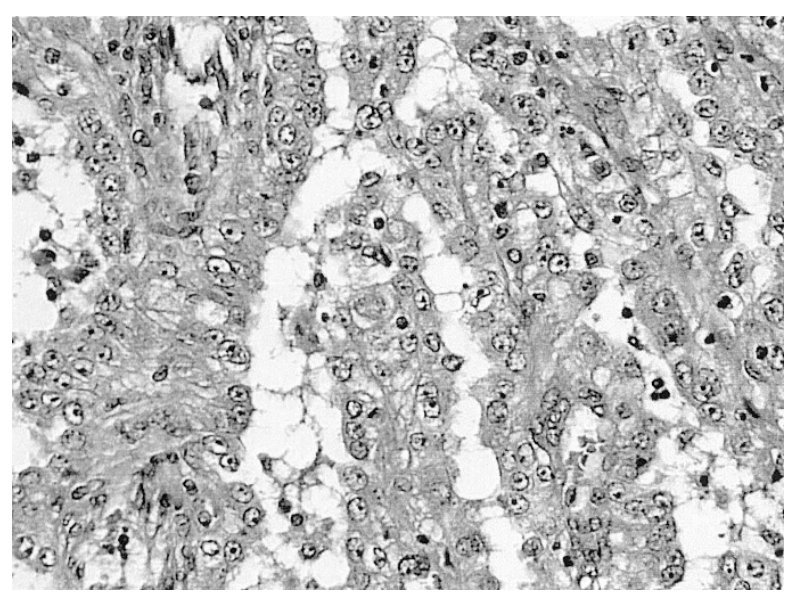

FIGURE 2. Type 2 papillary renal cell carcinoma: tumor papillae covered by large eosinophilic cells with irregular nuclei. 
tumor (Fuhrman Grade 3 in 4 cases, Fuhrman Grade 2 in one case), 1 in 6 had a Type 1 tumor (Fuhrman Grade 3). Among the six metastatic patients, two were Stage pT3, two were Stage pT2, and two were Stage pT1.

\section{Immunohistochemistry}

20/37 (54\%) tumors were positive for MUC1: 18/25 (72\%) Type 1 tumors and 2/12 (16.6\%) Type 2 tumors. In Type 1 the staining was diffuse $(>50 \%$ of stained cells) with an apical cellular distribution (Fig. 3). In Type 2, the staining was always focal (5-10\% of tumor cells; Fig. 4). No staining with MUC1 was observed in tumors with metastatic evolution (Type 1 and 2).

\section{Statistical Analysis}

Type 2 tumors were significantly associated with a higher Fuhrman grade than Type $1(P<.001)$. No statistical relationship was observed between the pT category, the patients' age, the sex, the tumor size, and the histological type. Studying survival

TABLE 1. Histological and Immunohistochemical Findings in Subtypes of Papillary Renal Cell Carcinoma

\begin{tabular}{ccc}
\hline Parameters & Type 1 & Type 2 \\
\hline No. of tumors & 25 & 12 \\
TNM & 19 & 8 \\
T1 & 6 & 2 \\
T2 & 0 & 2 \\
T3 & 0 & 0 \\
T4 & & \\
Fuhrman grade & 2 & 0 \\
G1 & 21 & 4 \\
G2 & 2 & 8 \\
G3 & 0 & 0 \\
G4 & & 2 \\
MUC1 staining & 18 & 10 \\
+ & 7 & \\
- & &
\end{tabular}

+ , positive staining; - , negative staining

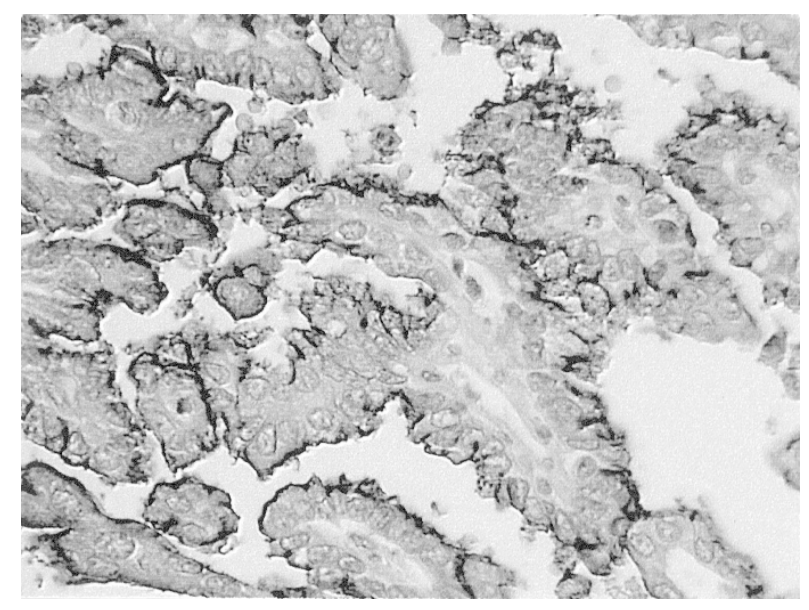

FIGURE 3. Type 1 papillary renal cell carcinoma: diffuse apical MUC1 expression.

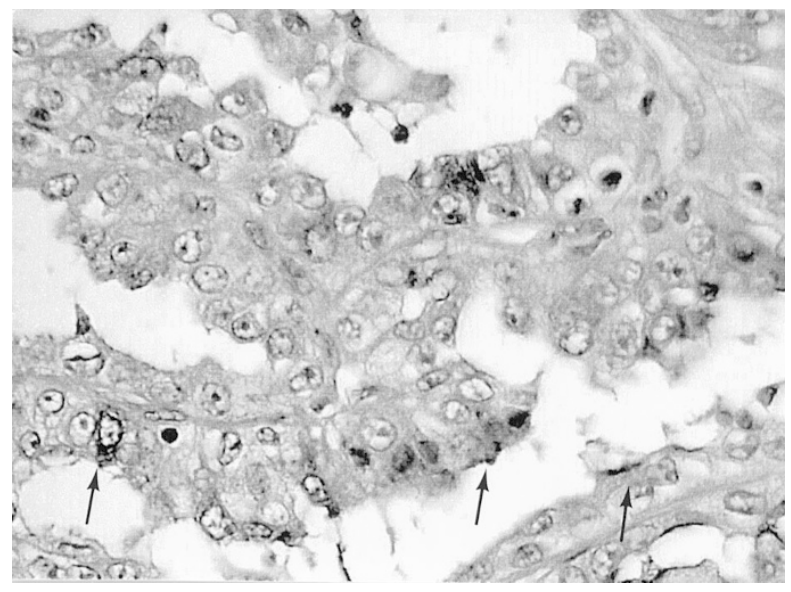

FIGURE 4. Type 2 papillary renal cell carcinoma: rare and focal MUC1 expression (arrows).

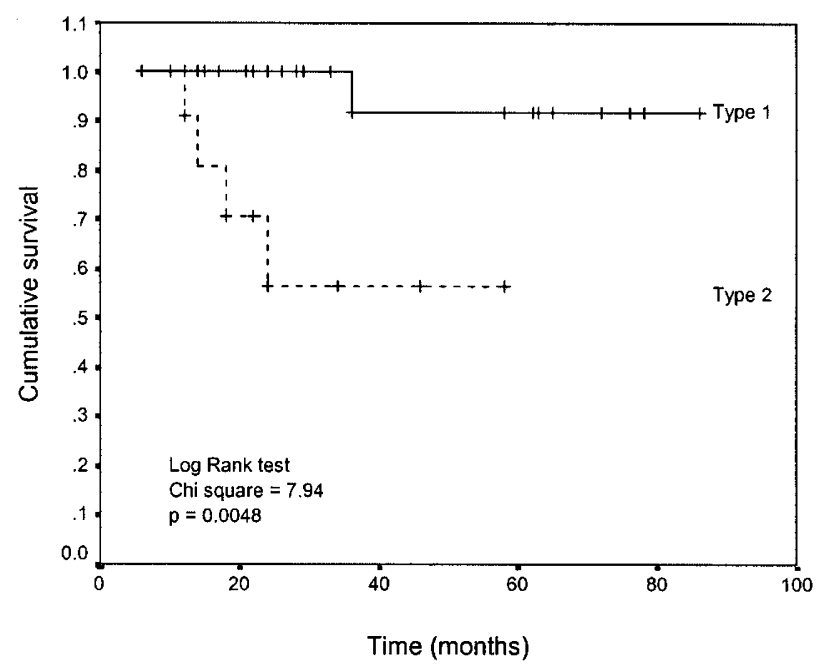

FIGURE 5. Kaplan-Meier survival curves for patients divided according to histological type.

curves, we observed that Type 2 was significantly more frequently associated with the metastatic spread and a poorer outcome than Type $1(P<.005$; Fig. 5). The Fuhrman grading was also a prognostic factor, with a difference between low Fuhrman grades (Grades 1 and 2) and high Fuhrman grade (Grade 3; $P<.005$ ). The pT category was not predictive of the outcome. MUC1 expression was more significantly associated with Type $1(P<.005)$, but MUC1 expression was not correlated with the outcome. Because of the moderate number of events, no multivariate analysis was carried out.

\section{DISCUSSION}

Papillary renal cell carcinoma was individualized from other renal cell carcinomas by its predominantly papillary or tubulo-papillary architecture ( $>75 \%$ of the tumor; 1 ). Genetic studies of papillary renal cell carcinoma have confirmed that it is a real separate entity with specific recurrent chromo- 
somal abnormalities, trisomy of chromosomes 7 and 17, and no alteration of chromosome 3 (11). The prognosis of papillary renal cell carcinoma remains debatable in the literature. Previous studies reported a better prognosis than conventional clear renal cell carcinoma, but this notion is extensively discussed (2, 10-13). Recently, Delahunt and Eble (3) have proposed to distinguish two morphologic types of papillary renal cell carcinoma, based on microscopic criteria. Using this classification the authors observed that the Type 2 tumor was associated with a larger tumor size, a higher Fuhrman grade (Grade 3 common) and a more advanced stage (T3-4 TNM) in comparison with the Type 1(3). Several other studies confirmed that papillary renal cell carcinomas composed of Type 1 have a lower-grade and a lower-stage than Type 2 (14-16). In our series, Type 1 tumor was more frequent than Type 2. The Fuhrman grade was significantly higher in Type 2 (Grade 3 frequent) with no Grade 1. In contrast, the stage TNM and the tumor size were not significantly different between Type 1 and 2 . In a more recent publication, Delahunt et al. (4) concluded that morphologic typing of papillary renal cell carcinoma is an independent predictive factor of outcome on multivariate analysis. Indeed they showed that Type 2 tumor was independently associated with the global survival. In their study, the nuclear grade and the pathological stage were not predictive of the outcome. Onishi et al. (15) confirmed also that the prognosis is better in basophilic tumors (Type 1) than in eosinophilic tumors (Type 2). In the present study, we have shown that Type 2 tumors are significantly associated with metastatic progression and a poorer survival rate than Type 1 . These findings suggest that patients with Type 2 tumors should benefit from a more strict follow-up.

In our series, the TNM stage was not significantly associated with prognosis, but we observed, like other authors, that the Fuhrman grade remains a valuable prognostic factor of papillary renal cell carcinomas $(10,12,14)$.

The biological and genetic basis of different subtypes of papillary renal cell carcinomas remains unclear. Jiang et al. (17), using comparative genomic hybridization found that gains of chromosomes $7 p$ and $17 p$ were more frequently encountered in Type 1 than in Type 2. Interestingly, these authors identified also Xp deletions in tumors with a poor outcome. But unfortunately, these deletions $\mathrm{Xp}$ were not associated with a particular morphologic subtype. Delahunt et al. (4), studying cell cycle markers (Ki-67, AgNORs), have demonstrated significant differences between Type 1 and 2. Indeed, Ki-67 index and AgNORs score were higher in Type 2 than in Type 1, suggesting a more aggressive biological feature of Type 2 .
In the present series, we have investigated the expression of MUC1 in the two subtypes of papillary renal cell carcinomas. MUC1 belongs to the family of human mucins, which are large O-glycoproteins expressed by many epithelial cells. MUC1 is a transmembrane mucin that is expressed in many normal glandular and carcinomatous cells (5). MUC1 is known to be frequently up-regulated in carcinoma. This overexpression in tumor cells is often associated with a loss of the apical polarity observed in normal cells (18). This abnormal overexpression with loss of polarity is suspected to destabilize cell-cell and cell-extracellular matrix interactions and then to favor metastases (1920). In the normal kidney, MUC1 is largely expressed in the convoluted distal tubules and in collecting ducts with an apical pattern staining. In clear renal cell carcinoma, MUC1 is frequently up-regulated, and the level of expression is correlated both with the Fuhrman grade and the survival rate (7-9). So MUC1 is overexpressed in high-grade tumors and is inversely correlated with prognosis (7-9).

In papillary renal cell carcinomas, no previous study has investigated MUC1 expression. We demonstrated MUC1 expression in $54 \%$ of papillary renal cell carcinomas. We observed that MUC1 was predominantly expressed in Type 1 $(72 \%)$ with a respect of the apical polarity seen in normal renal distal convoluted tubules. In Type 2, MUC1 expression was lost in tumors with only a focal and weak staining in two cases (Fig. 4). MUC1 expression was correlated with the Type, but no relationship was found with Fuhrman grade nor prognosis.

In conclusion, our findings confirmed that the morphologic subtyping is an important prognostic factor of papillary renal cell carcinomas. Type 2 tumor is associated with higher Fuhrman grade, metastatic progression, and poorer prognosis. We have also shown that MUC1 expression is polarized in Type 1 tumor and is down-regulated in Type 2 . We hypothesize that the loss of MUC1 expression may be a marker of dedifferentiation in Type 2 papillary renal cell carcinoma. [13]

\section{REFERENCES}

1. Bostwick DG, Eble JN. Urologic surgical pathology, 1st ed. St. Louis: Mosby, 1997. p. 90-2.

2. Amin MB, Amin MB, Tamboli P, Javidan J, Stricker H, DePeraldata Venturina MD, et al. Prognostic impact of histologic subtyping of adult renal epithelial neoplasms: an experience of 405 cases. Am J Surg Pathol 2002;26:281-91.

3. Delahunt B, Eble JN. Papillary renal cell carcinoma: a clinicopathologic and immunohistochemical study of 105 tumors. Mod Pathol 1997;10:537-44.

4. Delahunt B, Eble JN, McCredie MRE, Bethwaite PB, Stewart $\mathrm{JH}$, Bilous MA. Morphologic typing of papillary renal cell 
carcinoma: comparison of growth kinetics and patients survival in 66 cases. Hum Pathol 2001;32:590-5.

5. Gendler SJ, Spicer AP, Lalani EN, Duhig T, Peat N, Burchell J, et al. Structure and biology of a carcinoma-associated mucin, MUC1. Am Rev Respir Dis 1991;144:S42-7.

6. Taylor-Papadimitriou J, Burchell J, Miles DW, Dalziel M. MUC1 and cancer. Biochem Biophys Acta 1999;1455:30113.

7. Kraus S, Abel PD, Nachtmann C, Linsenmann HJ, Weidner W, Stamp GW, et al. MUC1 mucin and trefoil factor 1 protein expression in renal cell carcinoma: correlation with prognosis. Hum Pathol 2002;33:60-7.

8. Fujita K, Denda K, Yamamoto M, Matsumoto T, Fujime M, Irimura T. Expression of MUC1 mucins inversely correlated with post-surgical survival of renal cell carcinoma patients. Br J Cancer 1999;80:301-8.

9. Leroy X, Zerimech F, Zini L, Copin MC, Buisine MP, Gosselin $\mathrm{B}$, et al. MUC1 expression is correlated with nuclear grade and tumor progression in pT1 stage renal clear cell carcinoma. Am J Clin Pathol 2002;118:47-51.

10. Fuhrman SA, Lasky LC, Simas C. Prognostic significance of morphologic parameters in renal cell carcinoma. Am J Surg Pathol 1982;6:655-63.

11. Kovacs G, Fuzesi L, Emanuel A, Kung HF. Cytogenetics of papillary renal cell tumors. Genes Chromosomes Cancer 1991;3:249-55.

12. Amin MB, Corless CL, Renshaw AA, Tickoo SK, Kubus J, Schults DS. Papillary (chromophil) renal cell carcinoma: histomorphologic characteristics and evaluation of conventional pathologic prognostic parameters in 62 cases. Am J Surg Pathol 1997;21:621-35.
13. Lager DJ, Huston BJ, Timmerman TG, Bonsib SM. Papillary renal tumors. Morphologic, cytochemical, and genotypic features. Cancer 1995;76:669-73.

14. El-Naggar AK, Ro JY, Ensign LG. Papillary renal cell carcinoma: clinical implication of DNA content analysis. Hum Pathol 1993;24:316-21.

15. Onishi T, Ohishi Y, Goto H, Suzuki M, Miyazawa Y. Papillary renal cell carcinoma: clinicopathological characteristics and evaluation of prognosis in 42 patients. Br J Urol 1999;83:93743.

16. Mydlo JH, Weinstein R, Misseri R, Axiotis C, Thelmo W. Radiologic, pathologic and molecular attributes of two types of papillary renal adenocarcinomas. Scand J Urol Nephrol 2001;35:262-9.

17. Jiang F, Richter J, Schraml P, Bubendorf L, Gasser T, Sauter $\mathrm{G}$, et al. Chromosomal imbalances in papillary renal cell carcinoma: genetic differences between histologic subtypes. Am J Pathol 1998;153:1467-73.

18. Rahn JJ, Dabbagh L, Pasdar M, Hugh JC. The importance of MUC1 cellular localization in patients with breast carcinoma. An immunohistologic study of 71 cases and review of the literature. Cancer 2001;91:1973-82.

19. Wesseling J, Van Der Valk SW, Vos HL, Sonnenberg A, Hilkens J. Episialin (MUC1) overexpression inhibits integrinmediated cell adhesion to extracellular matrix components. J Cell Biol 1995;129:255-65.

20. Satoh S, Hinoda Y, Hayashi T, Burdick MD, Imai K, Hollingsworth MA. Enhancement of metastatic properties of pancreatic cancer cells by MUC1 gene encoding an antiadhesion molecule. Int J Cancer 2000;88:507-18. 